DOI: https://doi.org/10.14232/actahisp.2021.0.101-111

\title{
BARCELONA COM A ESPAI NARRATIU HORITZONTAL I VERTICAL EN L'OBRA DE JUAN MARSÉ
}

\author{
DóRa FAIX
}

Universitat Eötvös Loránd de Budapest

\begin{abstract}
Resum: En l'obra de Juan Marsé l'acció se situa en un espai literari molt típic que comença a formar-se ja a partir de Encerrados con un solo juguete, la primera novel·la de l'autor. Es tracta d'un espai basat en la realitat extraliterària -la ciutat de Barcelona i alguns del seus barris- que dintre del text es relaciona amb pràcticament tots els elements de la narració, molt especialment amb els personatges i amb la seva acció. Les teories de Gabriel Zoran i Gaston Bachelard permeten descobrir com aquest espai es converteix en portador del valor simbòlic del text literari i pot contribuir a la interpretació. En Últimas tardes con Teresa aquest espai ja està completament configurat i en novel·les posteriors estarà implícitament present amb les mateixes característiques.
\end{abstract}

Paraules clau: Juan Marsé, Barcelona, espai literari, espai horitzontal, espai vertical.

Abstract: In the work of Juan Marsé, the action is located in a very typical literary space that begins to form from Encerrados con un solo juguete, the author's first novel. It is a space based on the extraliterary reality -the city of Barcelona and some of its neighborhoods- that within the text relates to practically all the elements of the narrative, especially the characters and the action. The theories of Gabriel Zoran and Gaston Bachelard allow us to discover how this space contains the symbolic value of the text and can contribute to the interpretation. In Últimas tardes con Teresa this space is already fully configured and in Juan Marsé's later novels will be implicitly present with the same characteristics.

Keywords: Juan Marsé, Barcelona, Literary Space, Horizontal Space, Vertical Space.

\section{Barcelona com a espai literari en l’obra de Juan Marsé}

L'espai literari de Juan Marsé es pot comparar amb universos narratius de fama mundial com el Yoknapatawpha de Faulkner, el Macondo de Gabriel García Márquez, la Regió de Juan Benet, i també amb els creats per escriptors espanyols més recents, com el territori de Celama de Luis Mateo Díez o el poble de Mágina d’Antonio Muñoz Molina. En el cas de Marsé estem ubicats a Barcelona, una ciutat que té un evident referent extratextual per al lector, mentre que Yoknapatawpha, Macondo, Regió, Celama o Mágina generen un fenomen d'autoreferencialitat en el qual els espais literaris creats es refereixen, en primera instància, a si mateixos.

Segons Benjamín Prado, 
Barcelona com a espai narratiu horitzontal i vertical en l'obra de Juan Marsé

Tal vez una de las razones por las que Juan Marsé nunca podría haber sido William Faulkner, Juan Carlos Onetti o Gabriel García Márquez es que su Barcelona es justo lo contrario de Yoknapatawpha, Santa María y Macondo: no es un territorio imaginario en el que suceden historias que simbolizan la realidad, sino una ciudad auténtica habitada por personajes dos veces ficticios, la primera porque son inventados y la segunda porque fingen no ser ellos y tratan de escapar de sus vidas a base de negarles, de contar y escuchar historias que les hagan sentir a ellos y creer a los demás que están en otra parte y les espera un destino diferente (Prado, 2011: 5).

Aquest paràgraf condensa aspectes fonamentals de l'espai narratiu de Marsé: per una banda el seu caràcter realista, per l'altra la seva estreta vinculació amb els personatges i amb l'acció. En realitat, és un espai que es relaciona amb pràcticament tots els altres elements de la narració: a més dels esdeveniments i els personatges, també amb el temps, l'autor i lector implícits, així com amb el propi discurs narratiu. Per tot allò, constitueix un dels aspectes més importants dels textos de Juan Marsé. Utilitzant les paraules d'Antonio Garrido Domínguez (que, al seu torn, segueix les idees de Mijail Bajtín), "su trascendencia es tal que se puede elaborar [...] una historia de la novela fundamentada en este factor" (Garrido, 1996: 207). De fet, diverses novel·les de Marsé es poden descriure tenint com a punt de partida l'espai narratiu. Ja en la seva primera novel·la, Encerrados con un solo juguete (1960), l'acció s'emmarca en l'espai narratiu que es configurarà en les obres següents, per constituir un element fonamental de Últimas tardes con Teresa (1966), Si te dicen que caí (1973), Un día volveré (1982), El amante bilingüe (1990), El embrujo de Shanghai (1993), Rabos de lagartija (2003) o Caligrafía de los sueños (2011). En aquestes novel·les, al mateix temps, es pot descobrir una certa variació: algunes il·lustren més que d'altres algun aspecte significatiu de l'espai narratiu, que, tot i ser el mateix, cada vegada juga un nou paper i enriqueix el seu significat simbòlic.

\section{Encerrados con un solo juguete i el nivell topográfic horitzontal}

En Encerrados con un solo juguete (1960) comença a construir-se l'univers tan propi de l'autor, i dins d'ell l'espai narratiu. Els esdeveniments es desenvolupen a Barcelona, la ciutat natal de Juan Marsé, on va passar la seva infància i adolescència durant la postguerra espanyola. Però el text no només reflecteix la vida dels joves d'aquella època, sinó també la de la capa més baixa de la societat. Per aquesta raó es configura un ambient dur, dramàtic i caòtic, en el qual la violència, els odis encara frescos de la guerra i la misèria imperen en la vida dels personatges i converteixen aquests barris en "metafóricos microcosmos de la postrada España del franquismo" - com diu Fernando Valls (2003: 70). 


\section{Dóra Faix}

Els plantejaments de Gabriel Zoran en el seu article titulat "Towards a Theory of Space in Narrative", de 1984, en el qual distingeix tres nivells d'estructuració de l'espai (en relació amb la història, la trama i el discurs, respectivament), són especialment fructífers per a la interpretació d'aquesta primera novel·la de Marsé. En el primer nivell, anomenat per Zoran "nivell topogràfic", podem detectar una sèrie d'oposicions que corresponen a l'organització horitzontal i vertical del món. Pel que fa a la primera: ciutat i poble, centre i perifèria, interior i exterior, llunyana i propera; quant a la segona, avall i amunt (1984: 316). La presència de la ciutat (dins de la qual la perifèria té un paper especialment important), els llocs són clarament identificables a través d'alguns signes lingüístics. De vegades s'esmenta explícitament la ciutat de Barcelona, altres els personatges passen per una sèrie de llocs que el lector pot equiparar amb carrers, places i llocs concrets d'aquesta ciutat, com la plaça de Lesseps, la Gran Via (de les Corts Catalanes), la plaça de Catalunya, les Rambles, el carrer San Pablo, la República Argentina, el Passeig de Gràcia, La Via Layetana, el parc Güell, Montjuich o l'estació de França. Aquests topònims tenen un referent extratextual verificable, que Greimas anomena "transposiciones metasemióticas" (Greimas citat per Pimentel, 2001: 30). Una referència d'aquest tipus pot ser, per exemple, un plànol de la ciutat o qualsevol discurs que s'hagi fet sobre la mateixa. L'essencial és que permetin al lector interessat corroborar la identificació de Barcelona. Dintre d'aquest text, la il·lusió de la realitat és tan forta que l'espai literari sembla un reflex de la realitat extratextual.

Pel que fa a l'oposició ciutat versus poble, en Encerrados con un solo juguete l'acció s'ambienta bàsicament a la ciutat, tot i que en rares ocasions també hi ha al·lusions a altres espais de fora, com Montgat, Girona, Alacant o Granada. Entre aquests, Montgat té especial rellevància des del punt de vista argumental, ja que representa l'inici de la relació amorosa dels dos protagonistes, Andrés i Tina. El lector no sap exactament què hi va passar, primer només hi apareixen al·lusions a alguna cosa, un episodi enigmàtic que només es revelarà cap al final de la novel·la. Montgat encara no posseeix la força expressiva i la dimensió ideològica que en algunes novel·les posteriors tindran els espais situats fora de Barcelona, però anticipa les cases d'estiueig a la platja que després es convertiran en un motiu recurrent.

En el mateix nivell topogràfic horitzontal val la pena observar els espais interiors i exteriors, especialment el primer, la importància del qual ja és evident des del paratext (concretament, el títol) de la novel·la. Els joves protagonistes viuen "encerrados con un solo juguete", és a dir, en un entorn tancat en el qual la seva única preocupació és l'amor (o el sexe). A més, ja en aquesta primera novel·la s'observa que l'espai no només constitueix l'àmbit on es desenvolupa l'acció, sinó que també té la funció connotativa de representar les formes de vida i l'esquema de valors dels personatges, i està estretament relacionat amb el seu destí. Els joves protagonistes estan deprimits per la situació en què es troben, però no tenen ni la força ni la imaginació per provocar canvis. L'amor o el sexe probablement no representen una sortida, una solució a la seva 
Barcelona com a espai narratiu horitzontal i vertical en l'obra de Juan Marsé

situació (tot i que el missatge final es pot considerar una mica reconfortant, ja que els joves protagonistes es mantenen junts, i l'Andrés sembla fer-se càrrec del seu destî).

Crida l'atenció la importància de les cases com a espai simbòlic de cadascun dels protagonistes. La vida d'aquests joves té lloc, en gran mesura, en espais interiors tancats i tristos -habitacions sense llum, cuines, passadissos, vestíbuls-. Res més eloqüent que l'íncipit de la novel·la, que se centra en la sala de l'Andrés, el protagonista. La descripció de l'espai no és molt detallada, però les breus referències són suficients per a evocar una atmosfera depriment i asfixiant: el dormitori és estret, petit, "un bloque de sombras translúcidas" (Marsé, 1960: 9), amb taques d'humitat al sostre, on la llum entra amb dificultat, on se sent "el pestucio de ceniceros repletos" (Marsé, 1960: 9). El narrador suscita una sèrie de sensacions visuals i olfactives per a estimular la imaginació del lector i crear una impressió que més tard també es verificarà en el comportament dels personatges: el desinterès, la impotència i la mandra que regna en les seves ànimes. També és expressiu l'altre espai interior de la novel·la: l'habitació de la protagonista femenina, Tina. "Pequeño, el menos frío de la casa, siempre oliendo fuertemente a tabaco rubio, de paredes azul pálido y desnudas" (Marsé, 1960: 17), reuneix a tots els membres de la família, tot $\mathrm{i}$ tenir un sol llum, una ràdio (que sempre es converteix en objecte de discussió, perquè tothom vol escoltar-la), i no tenir cap finestra. Es tracta d'un espai completament hermètic: no té sortida, ni tan sols existeix la possibilitat que hi entri una mica de llum (símbol de l'esperança). L'únic pis que podem considerar "obert" és el d'en Martin (el tercer personatge del triangle amorós), tanmateix les seves finestres no semblen complir la seva funció. En primer lloc, perquè l'habitant principal d'aquesta casa, la mare d'en Martin, és cec. Tal com diu el text, té els ulls fixats a les finestres "pero sin ver nada" (Marsé, 1960: 79), la seva mirada mai arriba "más allá de los cristales de su propia casa" (Marsé, 1960: 80). No obstant això, ella se’n recorda de les finestres de l'edifici oposat, que també són bastant especials, ja que o bé tenen els vidres trencats o bé les persianes sempre baixades. D'altra banda, Martin, al seu torn, utilitza aquestes finestres només per a espiar als veïns que viuen enfront de casa seva.

Resulta especialment interessant observar la casa de la Tina tenint com a punt de partida la determinació fenomenològica de les imatges de Gaston Bachelard. Aquest destaca l'espai interior, i molt concretament la casa, com "un ser privilegiado" (Bachelard, 2000: 27) associat a determinats valors, com la intimitat, el refugi (o la protecció), la nostàlgia (o els records) i el somni. Pel que fa a aquest últim, Bachelard afegeix que "el pasado, el presente y el porvenir dan a la casa dinamismos diferentes, dinamismos que interfieren con frecuencia, a veces oponiéndose, a veces excitándose mutuamente" (2000: 29-30). La casa de la Tina és, de fet, el lloc de la memòria i dels records (al seu interior sovint s'evoca el passat de la família), així com també dels somnis (és aquí on la noia parla de les seves ganes d'anar a viure amb el seu pare). Paral-lelament es produeix una trobada dinàmica entre el passat, el present $\mathrm{i}$ el futur: l'evocació del passat, en què el pare encara hi era present, accentua encara més la situació depriment del present, en la seva absència, i això és el que mou la Tina a somiar 


\section{Dóra Faix}

amb un futur en què abandonaria aquesta casa i seria molt més feliç vivint amb ell. També podem veure que, contràriament a la imatge originalment positiva que segons Bachelard podíem associar a la casa com a refugi o lloc segur, la casa de la Tina representa el contrari, perquè és aquí on es desenvolupa l'agressivitat i la violència. A més, si considerem -com Bachelard- la idea que la imatge de la llar que ens envolta per protegir-nos també representa el nostre propi cos, i com a tal, la nostra intimitat invulnerable, serà encara més rellevant que l'acte de violació tingui lloc precisament en aquest espai. La violació del cos també significa, doncs, que es vulnera la funció protectora de la casa. A més a més, és un acte en el qual estan implicats els altres habitants de la casa, les persones més properes a la Tina (especialment la mare, però també els dos germans) que des de l'inici de la història passen el seu temps a l'habitació de la Tina, però en aquest moment crucial surten de casa. En aquest context es pot entendre millor la reacció (o més aviat la falta de reacció) de la Tina, la seva passivitat o impotència en el moment de desenvolupar-se la violació.

Un altre espai rellevant de Encerrados con un solo juguete (i que també reapareixerà en la narrativa posterior de Marsé) és el bar, un lloc de trobada de diferents personatges. Pel que fa a la seva construcció narrativa, trobem un espai que es construeix a partir de la descripció del seu interior, i després passem al seu eixamplament cap al món exterior, de la manera següent:

Entró en el bar. Era un local grande con paredes pintadas de verde y azulejos hasta la altura de los hombros. Al fondo, en una ampliación hacia la izquierda, donde habían derruído una pared y ocupado un pequeño almacén de material de construcción estaban los billares y una gran vitrina llena de trofeos deportivos ganados por otra generación -la del dueño del bar, en su época de atleta y de miembro de una masa coral-, enormes copas oxidadas, banderines descoloridos y pancartas acumulando polvo en los estatuarios pliegues. Sobre una mesa de mármol se amontonaban tableros de ajedrez, barajas y juegos de dominó, y en otra, a su lado, los periódicos. Todos doblados por las páginas de fútbol.

El bar quedaba tres manzanas de edificios más abajo de la calle de Andrés, podía decirse que ya era otro barrio: no había en él ni la quietud ni el triste y viejo aire de abandono de su calle y todas las de aquella parte alta de la ciudad, llena de verjas chirriantes y de jardines descuidados, de antiquísimos y siempre desconocidos vecinos que decían buenos días o buenas noches y nada más, sin voz y como sufriendo, como si realmente presintieran lo estéril de las palabras en aquel sector olvidado. Cerca del bar, en cambio, las construcciones eran nuevas, altas, la gente también nueva, distinta, moviéndose como si tuviese otros problemas y con otra sonrisa menos difícil y fatigada (Marsé, 1960: 13). 
Barcelona com a espai narratiu horitzontal i vertical en l'obra de Juan Marsé

En el primer paràgraf citat es pot veure com arribem des de la visió de tota la barra fins a l'evocació dels detalls -des del moviment generalitzant fins al moviment particularitzant segons la terminologia utilitzada per Pimentel (2001: 22)-. I els objectes que es troben a la barra també tenen una forta connotació que fins i tot podem considerar ideològica: trofeus esportius, copes, penjolls i pancartes representen els herois i els triomfs de la generació anterior, mentre que el billar, els taulers d'escacs, les cobertes, els dòmino i els diaris -oberts sempre per les pàgines de futbol (Marsé, 1960: 85, 105 i 107) - corresponen a l'abúlia de la propera generació (els joves del present de la narració). Els més grans tenien les seves idees (polítiques), els seus ideals, i les copes i els trofeus representen les seves victòries, mentre que els joves es defineixen simplement pel joc, ja que no es dediquen a res més que a divertir-se. El valor connotatiu d'aquests objectes s'accentua en el conjunt de la novel·la amb la seva repetició o presència recurrent, $\mathrm{i}$ algunes digressions dels personatges fins i tot emfatitzen aquest contingut semàntic. La mateixa idea de la diferència entre les dues generacions s'expressa, per exemple, en els paràgrafs següents, en els quals també trobem una explicació o justificació del fenomen. Primer, a través d'un narrador en tercera persona, després a través de les paraules del mateix protagonista:

Las once y media. Andrés no podía oír un ruido ni ver apenas nada. Pero sabía que eran las once y media. Se volvió de cara a la pared y encogió las piernas. No le esperaba nada ni nadie, pertenecía a esa generación a la cual se le ha dado ya, al parecer, todo hecho -símbolos, victorias, héroes que venerar, mármoles que besar- y sin posibilidad de nueva senda, siquiera sin derecho a buscarla entre aquella marea de días prefabricados, dictados, que se posaban mansamente al pie del lecho todas las mañanas exigiendo ser calzados con los zapatos o vestidos con las ropas. Bostezó, el pulgar y el índice en las comisuras de los labios. El camino es llano, murmuró, y se puede recorrer con las manos en los bolsillos, callada y aburridamente (Marsé, 1960: 10).

En lo que a mí respecta, quisiera que te desengañaras un poco, mis problemas son otros. Quizá no tan importantes desde el punto de vista de papá, pero son, hoy por hoy, los únicos permisibles. Verás: yo no soy tan bueno como lo fue él, aunque te le recuerde en su juventud por muchas coincidencias de carácter, de ideas, o yo qué sé... Aunque quisiera, no podría ser como él, se debe a una circunstancia de época -y al decir eso pensó en ellos, adormecidos cada noche en la atmósfera del bar, ciegos, inconscientes, con los sombreros impermeables puestos, el mismo corte de pelo en las nucas, la misma tonadilla en los labios, el mismo aburrimiento en los ojos-. Sí, se debe sin duda a una circunstancia de época (Marsé, 1960: 103). 


\section{Dóra Faix}

Per últim, cal destacar el contrast entre els dos barris de la ciutat. Al barri on es troba el bar són diferents els edificis, també els habitants, tot l'entorn. Davant la tristesa i l'abandó que caracteritza el barri més pobre, les persones que habiten els edificis més alts i nous semblen tenir menys preocupacions. Aquesta idea s'expressa, per exemple, en la carta que dirigeix la Tina al seu pare:

[...] Vivimos todavía en este barrio tan aburrido. Unas calles más abajo ya es distinto, los chicos y las chicas se ven más a menudo, se divierten más, pero aquí, tan arriba de Barcelona, tan silencioso, y con tan poca gente y a medio conocer (Marsé, 1960: 233).

Amb aquestes paraules, el nivell topogràfic horitzontal, format per l'evocació estàtica de la ciutat, amb els seus carrers, bars i cases, es complementa amb l'eix vertical, que se relaciona immediatament amb la divisió de la societat, per tant té un significat simbòlic. Aquest arribarà al seu punt àlgid en un moment posterior de la narrativa de Juan Marsé, i sobretot en Últimas tardes con Teresa, amb la completa identificació entre personatges i espai.

\section{Protagonisme de l'espai i el nivell topográfic vertical dins Últimas tardes con Teresa}

Últimas tardes con Teresa (1966), la novel·la que es considera l'inici de la veritable carrera narrativa de l'escriptor i un dels llibres més significatius dels anys seixanta, va despertar l'interès de crítics i lectors per moltes raons, entre elles l'espai narratiu. És aquí on el seu tractament adquireix més èmfasi: la descripció esdevé una forma discursiva privilegiada i s'estableix definitivament el propi món narratiu de l'autor.

Tenim molt clar des del principi del text que l'escenari és la ciutat de Barcelona. El nom de la ciutat apareix 36 vegades, i encara és més difícil enumerar el nombre de vegades que s'esmenten carrers concrets, que en el seu ordre d'aparició són: els carrers Mandri, Pasteur, Muhlberg, Sardenya, Gran Vista, Escorial, Escudillers, del Doctor Boyé, Fontanella, Llorer, Cartagena, Garcilaso i les Rambles. Alguns d'ells apareixen diverses vegades, especialment les Rambles (nombrades 12 vegades) i el carrer Gran Vista (en 6 ocasions). Entre les places, el text al-ludeix a la Sanllehy, la del Pi, la del Teatre, la de Lesseps, la Real, de Joanich, la d'Espanya, la de la Font Castellana i la de Catalunya (amb una presència més cridanera de la primera, esmentada 8 vegades). Aquests carrers i places tenen una presència molt dinàmica en el text, ja que els personatges, principalment el Manolo, hi pugen i baixen constantment. Ho podem veure, per exemple, en el següent fragment, a l'inici de la novel·la: 
Barcelona com a espai narratiu horitzontal i vertical en l'obra de Juan Marsé

[...] el llamado Pijoaparte surgió de las sombras de su barrio vestido con un flamante traje de verano color canela; bajó caminando por la carretera del Carmelo hasta la plaza Sanllehy, saltó sobre la primera motocicleta que vio estacionada y que ofrecía ciertas garantías de impunidad (no para robarla, esta vez, sino simplemente para servirse de ella y abandonarla cuando ya no la necesitara) y se lanzó a toda velocidad por las calles hacia Montjuich (Marsé, 1990: 13).

Molts més exemples podrien servir per demostrar que, després del començament, el moviment del Manolo per la ciutat és constant. A més a més, es pot veure no només el desplaçament del personatge d'una zona de la ciutat a l'altra (motiu recurrent que representa la recerca del seu lloc en el món) sinó també una dinàmica que inclou, al mateix temps, una certa inseguretat (mitjançant les oposicions de llançar-se i frenar, córrer i aturar-se). Per tant, a més de l'existència d'un nivell horitzontal i vertical (que acabem d'observar en la primera novel·la de l'autor), també és rellevant el moviment constant del protagonista entre aquests nivells. El Manolo busca contínuament el seu lloc entre els dos mons (els barris alts i els barris baixos), però no encaixa en cap d'ells. Cal destacar l'expressió carreró sense sortida, que s'utilitza diverses vegades en el text, i es pot vincular al mateix problema.

[...] Montó en la motocicleta y se lanzó carretera abajo sumido en vagos y molestos remordimientos: el Cardenal tenía el extraño don de pellizcarle la conciencia. Por otra parte, la promesa hecha al Sans de llevar a las chicas a la playa, la idea de que se estaba metiendo en un callejón sin salida, se hacía particularmente aguda a medida que despuntaba el día (Marsé, 1990: 63).

[...] Manolo guardaba silencio: de pronto parecía desorientado: acaso porque muchas veces había tenido que correr perseguido de cerca por los vigilantes nocturnos, la angustiosa sensación de meterse sin querer en un callejón sin salida era en él muy frecuente y aguda (Marsé, 1990: 172).

[...] A mí no me hace cambiar ninguna golfa (a partir de este momento, y ya por todo el rato que seguiría allí sentado, la ceniza húmeda de los ojos de Hortensia se convirtió en una especie de succión, como de insecto voraz. Al mismo tiempo, la idea de que se estaba metiendo en un callejón sin salida crecía oscuramente en su interior). (Marsé, 1990: 173)

Curiosament, la Teresa també comparteix la situació del Manolo de trobar-se en un carreró sense sortida. I també vol trobar una solució. Així ho demostra una breu al·lusió feta en una escena en què està amb el seu amic Luis: 


\title{
Dóra Faix
}

\begin{abstract}
Comprendió que nunca escaparían de esta especie de callejón sin salida a no ser que uno de los dos hiciera algo en seguida: por ejemplo, habría bastado que él cogiera su mano al pasarle la botella de gin, o que se le ocurriera ponerle la sandalia que ella había dejado caer de su pie, cualquier cosa que implicara proximidad física. Pero como él no parecía dispuesto a dar el primer paso, se decidió a darlo ella [...] (Marsé, 1990: 116).
\end{abstract}

També crida molt l'atenció la freqüent menció dels barris de la ciutat. Cal afegir, però, que tot i que sorgeix la possibilitat de dibuixar un mapa basat en elements del text, aquest no seria del tot real. Es produeix exactament el mateix fenomen que revela Zoran pel que fa a l'estructura topogràfica de l'espai narratiu: "Algunes de les seves àrees estan en blanc, i en el món real pot no ser de gran utilitat per trobar el seu camí. Amb l'objectiu de llegir, però, proporciona una imatge prou clara del món" (Zoran, 1984: 316) ${ }^{1}$.

Entre els diferents barris de Barcelona, es posa especial èmfasi en el Mont Carmel i el Guinardó $^{2}$, on viuen els charnegos (els immigrants d'una regió diferent a Catalunya, especialment del sud d'Espanya, sobretot Múrcia i Andalusia), per contra de la capa burgesa acomodada que habita a les torres de Sant Gervasi (i que també sol tenir una casa d'estiueig). El mapa de Barcelona es configura com a resultat d'un procés de selecció dut a terme per l'escriptor per a revelar el nivell connotatiu i ideològic de la novel·la. Es tracta sobretot de desenmascarar, a través dels barris més pobres de la ciutat i el contrast, la cruel i invencible divisió de la societat i les seves conseqüències. Per a molts crítics i investigadors aquesta pot ser la base fonamental de la interpretació del text. La història d'amor entre la Teresa i el Manolo, una noia de l'alta societat catalana i un noi dels barris baixos, és només el pretext per a parlar de dos mons ben diferents: la capa adinerada (representada per ella) i la pobra, fins i tot miserable capa dels suburbis (encarnada en el protagonista masculî). La divisió entre la classe alta i la classe baixa està molt marcada, sembla que falta completament la classe mitjana.

Criden l'atenció els llargs paràgrafs que descriuen el Mont Carmel al començament de la novel·la. La primera part de la descripció abunda en reiteracions d'elements o motius -somni, estels, guerrer- que afecten la caracterització dels habitants del barri (entre ells la del Manolo) i destaquen el contingut ideològic de la descripció: la gent dels suburbis somia, vol aconseguir l'inabastable, i per aconseguir-ho, està disposat a lluitar. És en aquest context que el Manolo entra sobtadament en escena i la seva aparició és molt elaborada. El jove forma part del barri i de la gent que l'habita, i entre espai i personatge la correlació és tan estreta que podem fins i tot parlar d'un espai

1 Traducció meva de l'anglès.

2 Afegeixo, entre parèntesis, algunes dades numèriques: la paraula barri s'utilitza ni més ni menys que 94 vegades en el text, el Mont Carmel o simplement Carmel 78 i el Guinardó 10 vegades. 
Barcelona com a espai narratiu horitzontal i vertical en l'obra de Juan Marsé

personificat, un espai que a poc a poc es va convertint en personatge. Des de la primera pàgina de la novel·la, el protagonista no només es diu Manolo, sinó "el (tenebroso) hijo del barrio" (Marsé, 1990: 11) o "el joven del Carmelo" (Marsé, 1990: 160). Altres denominacions es refereixen al seu origen andalús a través de sobrenoms com "el murciano" (paraula que assenyala a Barcelona a qualsevol persona del sud, pertanyent a la classe baixa, i és utilitzada contínuament dintre de la novel·la no només en relació amb el Manolo) o "el joven del Sur" (expressió també utilitzada diverses vegades), que indiquen, a més de l'origen del protagonista, la seva posició com a immigrant. La Teresa, per contra, encarna el barri residencial de Sant Gervasi, districte de la burgesia rica, lloc tranquil de festes, on elegants parelles passegen pels carrers. Per a representar el contrast entre els dos mons, l'autor també introdueix escenaris fora de Barcelona, especialment la vila de platja amb el seu petit port que també forma part del món de la capa rica de la societat.

Entre els mons representats, més èmfasi recau en el del Manolo. El barri del Carmelo, a més de ser descrit al llarg de la novel·la com el propi espai del jove protagonista, és constantment evocat per la Teresa, que està interessada i apassionada no només per ell, sinó també pel seu barri. L'entusiasme de la jove progressista va lligat al rerefons ideològic de la novel·la ja que la Teresa es considera una defensora de la causa dels necessitats, dels treballadors dels suburbis i, com a salvadora, li encanta enfonsar-se en el món del Manolo.

L'espai de transició entre els dos mons és la clínica on entra la Maruja (amant del Manolo i criada de la família de Teresa). Aquesta zona no és exclusiva de cap capa social, per la qual cosa és l'espai ideal per iniciar-se les relacions romàntiques entre la Teresa i el Manolo. Abans que hi hagi una relació directa entre els dos personatges, ja s'han produit trobades fugaces -al mateix festival, a l'inici de la novel·la, al costat de la porta de la casa de la Teresa (també un lloc de transició entre els dos mons)- però el contacte real entre ells només es pot començar a la clínica.

També té rellevància Ronda, lloc de naixement del Manolo, que representa els orígens del protagonista. Orígens incerts, a més, perquè no se sap amb certesa qui era realment el seu pare (el marquès per al qual treballava la seva mare o un convidat anglès del marquès). Aquest desarrelament és important en la formació del personatge que vol allunyar-se no només del lloc on va néixer, sinó també intenta desvincular-se del seu passat i crear la seva pròpia identitat ja allunyada d'aquest lloc. Però abans de fer-ho, ha de passar una cosa que li mostra el camí a seguir: la seva trobada amb els Moreaus, una rica família francesa per a la qual treballa com a guia. Ells, especialment la mare, proposen al Manolo un futur millor a França, i encara que no es compleix el pla, serveix com a primer senyal per al Manolo de la possibilitat d'escalar socialment, projecte que finalment intenta dur a terme a través de la Teresa.

En Últimas tardes con Teresa, l'espai literari esdevé, per tant, un element indispensable del camp semàntic ideològic de la novel $\cdot$ la, i aquest èmfasi és nou dins de la narrativa de Marsé. A més, a partir d'aquesta novel·la, l'autor ja no haurà d'inserir en les seves obres 


\section{Dóra Faix}

textos descriptius llargs. Amb la simple menció d'algun topònim -Carmelo, Guinardó, etc.- el text es referirà no només a la Barcelona del món real, sinó també a la ciutat fictícia, a l'espai diegètic propi de Marsé, ja configurat en les novel·les anteriors. De la mateixa manera, també es mantindran presents tant l'aspecte horitzontal com el vertical de l'espai literari barceloní, amb tot el seu contingut simbòlic i metafòric, però ho faran ja implícitament en les novel·les posteriors de l'autor.

\section{Referències bibliogràfiques}

Bachelard, Gaston (2000). La poética del espacio. Buenos Aires: Fondo de Cultura Económica.

Garrido Domínguez, Antonio (1996). El texto narrativo. Madrid: Editorial Síntesis.

Marsé, Juan (2005). Ronda del Guinardó. Edición de Fernando Valls. Barcelona: Crítica.

Marsé, Juan (1990). Últimas tardes con Teresa. Vigésimo segunda edición. Barcelona: Seix Barral.

Marsé, Juan (1960). Encerrados con un solo juguete. Barcelona: Seix Barral.

Pimentel, Luz Aurora (2001). El espacio en la ficción. México D. F.: Siglo XXI Editores.

Prado, Benjamín (2011). Los sueños de Juan Marsé son mentira. Cuadernos Hispanoamericanos, 729. 5-7.

Valls, Fernando (2003). La realidad inventada. Análisis crítico de la novela española actual. Barcelona: Crítica.

Zoran, Gabriel (1984). Towards a Theory of Space in Narrative. Poetics Today.The Construction of Reality in fiction, 5(2). 309-335. 